\title{
Duration of load behaviour of a glued shear plate dowel joint
}

\author{
Gustaf Larsson $^{1} \cdot$ Per Johan Gustafsson ${ }^{1} \cdot$ Erik Serrano $^{1} \cdot$ Roberto Crocetti $^{2}$
}

Received: 5 March 2019 / Published online: 5 November 2019

(c) The Author(s) 2019

\begin{abstract}
An experimental study on the duration of load effects in a glued shear plate dowel joint was conducted. The joint design features a single large diameter dowel for load transfers between members, via external steel plates, which are bonded to the timber with a low stiffness bond line. Due to the low bond line stiffness, the timber element is subjected to a close to uniform shear stress distribution over the bond area. The study comprises a total of 80 test specimens loaded in shear, both parallel and perpendicular to the grain, at three load levels in the range of $50-80 \%$ of the short-term failure load. All specimens failed within approximately 110 days in outdoor sheltered conditions during which time deformations were recorded for one specimen of each type and load level. The study found a significantly larger influence of duration of load for this dominant shear action than what is reported in the literature for bending tests. The method of ranked stress was used to determine a suggested reduction factor $\mathrm{k}_{\text {mod }}$ for the shear plate dowel joint to 0.10 and 0.30 for parallel and perpendicular loading, respectively. This is a rough estimate based upon a 50-year extrapolation of 4-month data. Thus, it must be concluded that the studied shear plate dowel joint is not efficient in terms of long-duration loads in outdoor sheltered climate, and that further studies are needed in order to verify the use in other climates. It is also evident in this study that there is a lack of knowledge and empirical evidence on the duration of load effects in timber for shear loading.
\end{abstract}

\begin{abstract}
Abbreviations
SPDJ Shear plate dowel joint

DOL Duration of load

SBR Styrene-butadiene rubber

GLT Glued laminated timber
\end{abstract}

\section{Introduction}

This paper investigates the duration of load effects in a glued shear plate dowel joint (SPDJ), a novel connection designed for use in heavy timber systems. An efficient on-site assembly is ensured using a single large diameter dowel (Crocetti et al. 2010; Kobel 2011; Yang et al. 2015). A premature shear plug failure is avoided using an externally bonded steel plate, which is attached to the timber with a bond line of low stiffness yet high fracture energy (Larsson et al. 2018;

Gustaf Larsson

gustaf.larsson@construction.lth.se

1 Division of Structural Mechanics, Lund University, P.O. Box 118, SE-221 00 Lund, Sweden

2 Civil and Architectural Engineering, Building Materials, School of Architecture and the Built Environment (ABE), KTH, Stockholm, Sweden
Gustafsson 2007). This is realised by the use of a rubber foil, which is vulcanised to the steel plate and bonded to the timber using adhesives. Such a resilient bond line enables a close to uniform shear stress distribution over the entire bond area, thus increasing the load carrying capacity considerably. An exploded illustration of the SPDJ is found in Fig. 1.

The rubber foil is thus necessary for the strength of the connection, but also enables the possibility to design the connection stiffness (Larsson 2016) by choosing specific rubber mixtures and/or thickness of the foil. However, introducing a rubber foil in the load carrying system poses a new set of challenges, including duration of load (DOL) effects especially regarding rubber creep (Austrell 1997) and timber subjected to shear loading.

While well-documented in bending (Wood 1951; Pearson 1972; Madsen 1971; Hoffmeyer 1990), the DOL behaviour of timber subjected to shear loading is considerably less investigated. Shear blocks have been studied by Leont'ev (1961) in a comprehensive 10-year indoor study on clear wood specimens loaded parallel to the grain, without climate control. His findings suggest that timber in shear is more affected by DOL than bending, suggesting a reduction factor for a 50 -year loading of 0.3 compared to 0.5 for bending (Pearson 1972). 


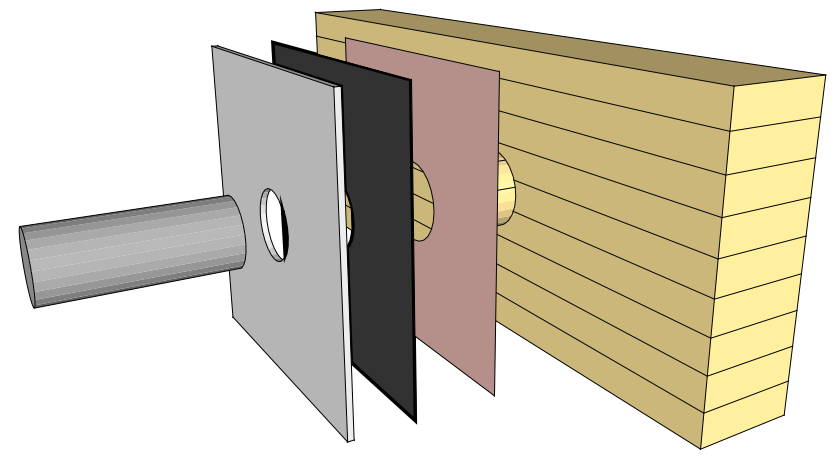

Fig. 1 Exploded view of the shear plate dowel joint. From left: single steel dowel; steel plate with hole size matching the dowel; rubber foil vulcanized to the steel plate; structural adhesive and then the GLT member with oversized hole to ensure no direct contact between dowel and timber

The findings by Leont'ev are in conflict with the results from a study conducted by Spencer and Madsen (1986) on wooden torque tubes in close to controlled climate, who found the Madison curve (Wood 1951) conservative for normal levels of applied stress. Furthermore, the study indicates that strong material is more affected by duration of load effects. Similar conclusions were drawn in a previous torsion test by Madsen, in which identical test specimens were subjected to accelerated DOL testing in a stepwise ramp loading regime (Madsen 1975). See Gerhards (1977) for a comprehensive summary of conducted DOL studies. For this study, also the work of van de Kuilen (1999) who investigated DOL effects on three types of timber joints, some of which with dominant shear action, is of interest and will be used for comparing results.

The present paper aims to evaluate the structural behaviour of the shear plate dowel joint when subjected to longterm static loading. This DOL study comprises a comprehensive experimental test program of small scale SPDJ subjected to long-term static loading in outdoor sheltered conditions, both parallel and perpendicular to the grain. The reliability of the connection will be determined in terms of a reduction factor for the duration of load effects, $\mathrm{k}_{\text {mod }}$, similar to European standards.

\section{SPDJ specimens and test conditions}

The study was conducted on a $65 \times 65-20$ shear plate dowel joint, indicating a plate size of $65 \times 65 \mathrm{~mm}^{2}$ and a single dowel of $20 \mathrm{~mm}$ in diameter. The connection was tested both parallel and perpendicular to the grain, achieved using a tensile and a bending test setup, respectively, see Figs. 2 and 3. Considerably larger $120 \times 120-45$ SPDJs are mounted as supports in the tensile tests, which are designed not to fail during testing.
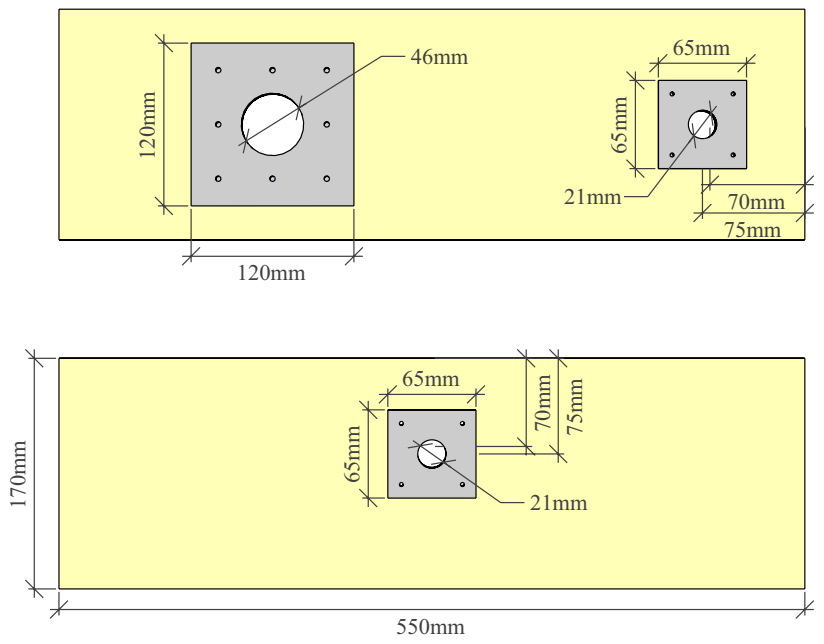

Fig. 2 Specimen dimensions, drawn to scale. Top illustration shows the specimen loaded parallel to the grain, and the bottom illustrates the specimen loaded perpendicular to the grain. The measurement system required eccentric hole placement, thus the centre of the steel plate is $75 \mathrm{~mm}$ from the edge, while the hole in the GLT is $70 \mathrm{~mm}$ from the edge

The joints are mounted on $550 \mathrm{~mm}$ long GLT elements with a cross-section of $80 \times 170 \mathrm{~mm}^{2}$ of strength class GL30c, manufactured in Töreboda, Sweden. The average moisture content of the GLT at the time of SPDJ production was $9.1 \%$, measured using a resistance type hand-held moisture meter. The average density was $480 \mathrm{~kg} / \mathrm{m}^{3}$.
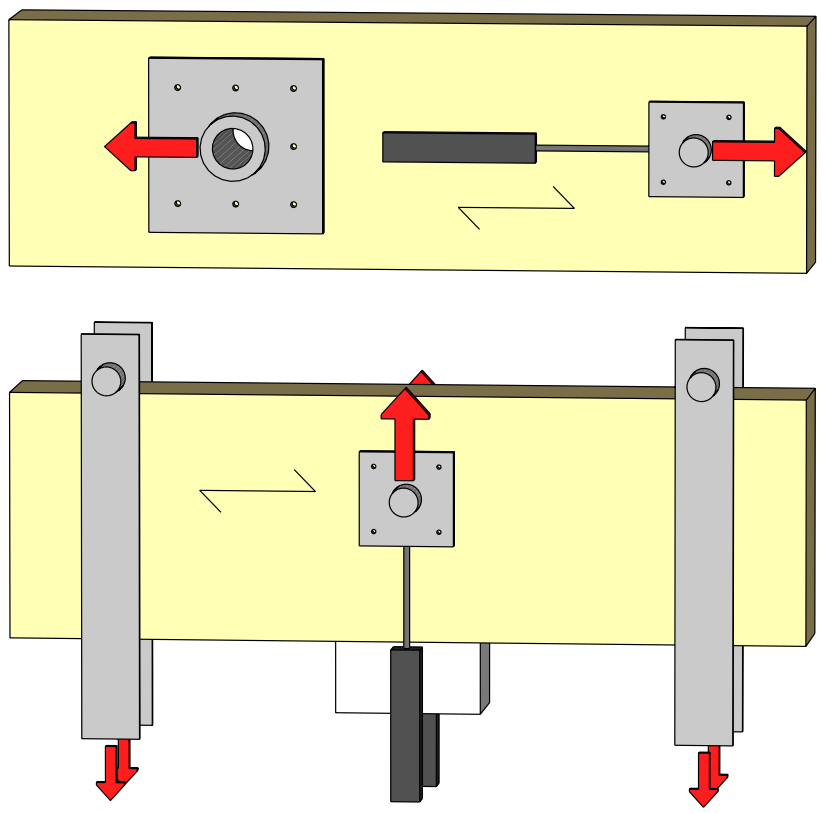

Fig. 3 Test setup including placement of the linear potentiometers as shown in black. Applied load and reaction forces are marked by arrows 
The steel plates with vulcanized rubber were produced in China by Wuxi Fuyo Tech. A mix of natural and SBR rubber with a thickness of 1.0-1.2 mm was vulcanized to the steel plates. In order to achieve a strong adhesive bond of the rubber to the GLT, the surface energy of the rubber was lowered by grinding and acid etching (Larsson et al. 2018). The rubber foil, vulcanised to the steel plate, was then bonded to the GLT using SikaForce 7710+ hardener 7010, a 2-component polyurethane adhesive. Curing pressure was applied using four $3.5 \times 35 \mathrm{~mm}$ screws, which were all removed from the plates prior to testing. For structural application it would be plausible to keep the screws inserted in order to increase the strength of the resilient bond line (Gustafsson 2007), but in this study, aiming at investigating the glued joint, the screws were removed.

In order to ensure force transfer through the joint by shear action of the plate rather than by contact between the dowel and the GLT element, a $35 \mathrm{~mm}$ hole was made in the timber at an end distance of 3.5 days, where $\mathrm{d}$ is the dowel diameter. A $21 \mathrm{~mm}$ hole was made in the steel plate, neatly fitting the $20 \mathrm{~mm}$ dowel. It should be noted that the steel plate is not centrically aligned over the hole in the GLT. This misalignment is not of general use in the SPDJ design, but necessary in this test series to ensure enough movement in the rig for failure registration by the logging system. This misalignment is visible in the failed specimen shown later in Fig. 5. The thickness of the GLT element was $80 \mathrm{~mm}$, for which the end grain was covered by acrylic paint to reduce moisture transport.

All specimens were conditioned to outdoor sheltered conditions for at least 1 month prior to testing or mounting. The short-term testing of the connection strength was thereafter conducted in indoor climate in February, but with minimal time to acclimatise in order to represent the DOL tests, which were conducted in the outdoor sheltered climate. The outdoor sheltered climate was characterized by a wellventilated, unheated and uninsulated timber barn located in southern Sweden, about $100 \mathrm{~km}$ from the sea at an altitude of $180 \mathrm{~m}\left(57^{\circ} 09^{\prime} \mathrm{N} 14^{\circ} 46^{\prime} \mathrm{E}\right)$. During January to March the $\mathrm{RH}$ was typically about $90 \%$ at an average temperature of $-2{ }^{\circ} \mathrm{C}$, while during May to July the $\mathrm{RH}$ was about $65 \%$ at an average temperature of $15{ }^{\circ} \mathrm{C}$. Relative humidity data is plotted in Fig. 9. The tests were all conducted or initiated in February 2018.
The long-term loading was achieved using rigs with weights and a cantilever pulley with a 1:6.30 ratio, meaning that a specimen load of $31 \mathrm{kN}$ required $500 \mathrm{~kg}$ of weight. Time to failure was recorded for all specimens, while plate slip was continuously recorded only for one DOL specimen of each type and load level. Possible interference between test rigs was minimized by ensuring enough space between rigs and installing cushioning under each load bracket.

\section{Results of short-term tests}

After 43 days of outdoor sheltered conditioning, the displacement controlled short-term quasi-static tests were performed in indoor climate with minimal time for the test specimens to acclimatise. The average specimen moisture content at time of testing was $11.7 \%(+2.6$ percentage points since production). Ten specimens of each type were tested at a rate of deformation of 1.2 and $0.6 \mathrm{~mm} / \mathrm{min}$ for the parallel and perpendicular specimens, respectively, resulting in an average total test duration of $10 \mathrm{~min}$. The results of these short-term referential tests are found in Table 1 and Fig. 4, showing that loading parallel to grain is on average $95 \%$ stronger than perpendicular loading.

For comparison, clear wood shear strengths of Norway spruce in RT and LT directions are also shown in Fig. 4 (Berblom Dahl 2009). The mean strength of the SPDJ was found greater than the corresponding clear wood shear strength, which indicates that the obtained failure mode is not a pure shear failure in a single direction. Furthermore, the coefficient of variation (COV) was found smaller for the SPDJ than the shear strength of clear wood specimens.

Primary failures were located in the bond line at all times, often followed by a secondary shear plug failure due to contact between dowel and GLT not further considered. The possible bond line failure modes considered here are (1) shallow wood shear failure, (2) failure in the adhesive layer including the interlayers, (3) vulcanization failure and (4) rubber failure. Typical failure modes can be seen in Figs. 5 and 6. All failure modes but rubber failure were found to various degrees at inspection of the failed surfaces, thus no single failure mode can be identified as a conclusive limiting factor. The failed parallel to grain specimens revealed that, on average, $60 \%$ of the bond line surface was subjected
Table 1 Short-term tests of small scale SPDJ with a total effective plate shear area of $6500 \mathrm{~mm}^{2}$ each

\begin{tabular}{lllll}
\hline Specimen & Direction & $\begin{array}{l}\text { Failure load 5th per- } \\
\text { centile (average) }\end{array}$ & $\begin{array}{l}\text { Shear stress at failure }{ }^{\mathrm{a}} \text { 5th } \\
\text { percentile (average) }\end{array}$ & COV \\
\hline Par-100 & Parallel to grain & $28.7(39) \mathrm{kN}$ & $4.40(5.9) \mathrm{MPa}$ & $12 \%$ \\
Perp-100 & Perpendicular to grain & $14.1(20) \mathrm{kN}$ & $2.15(3.0) \mathrm{MPa}$ & $18 \%$ \\
\hline
\end{tabular}

Ten specimens of each type were tested, thus the minimum failure load is equal to the 5 th percentile ${ }^{a}$ Determined by assuming uniformly distributed shear stress 


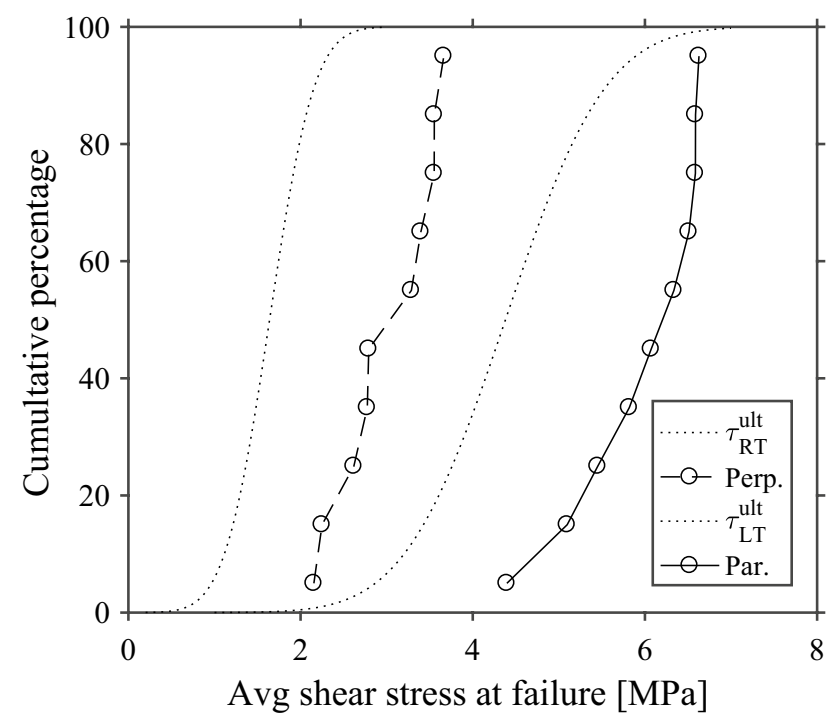

Fig. 4 Short-term strength of the SPDJ conditioned in outdoor sheltered conditions for 43 days, loaded both parallel and perpendicular to the grain. For comparison, dotted lines represent clear wood shear strengths in RT and LT directions, respectively (Berblom Dahl 2009)

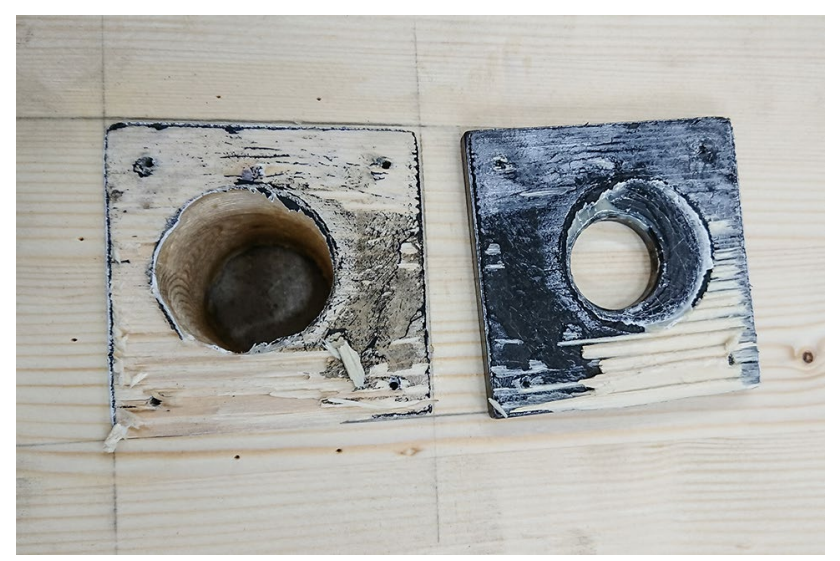

Fig. 5 Typical bond line failure of SPDJ loaded parallel to the grain from group Par-100. The specific specimen shows shallow wood shear failure $(25 \%)$ and failure in the adhesive layer including the interlayers $(75 \%)$

to adhesive failure, while $25 \%$ had a shallow wood failure. However, for the perpendicular to grain specimens, $85 \%$ of the failure surface was considered wood failure, while $12 \%$ adhesive failure, on average. The difference is due to a higher degree of rolling shear. It is evident that the adhesion between rubber and adhesive represents a weak link, which can possibly be improved by better quality control of the pre-treatment of the rubber. Some specimens of both types had weaknesses in the vulcanization, which should be, of course, eliminated by proper manufacturing techniques and quality controls.

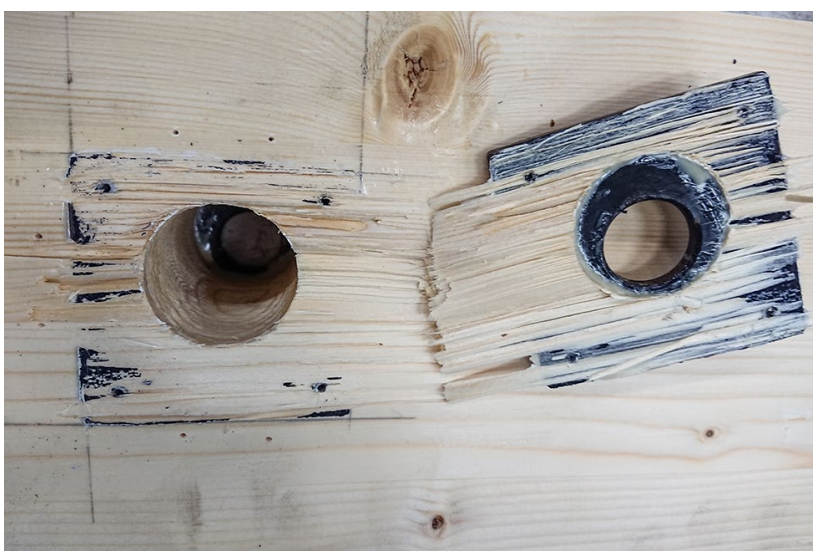

Fig. 6 Typical bond line failure of SPDJ loaded perpendicular to the grain from group Perp-100. The specific specimen shows shallow wood shear failure (90\%) and failure in the adhesive layer including the interlayers $(10 \%)$

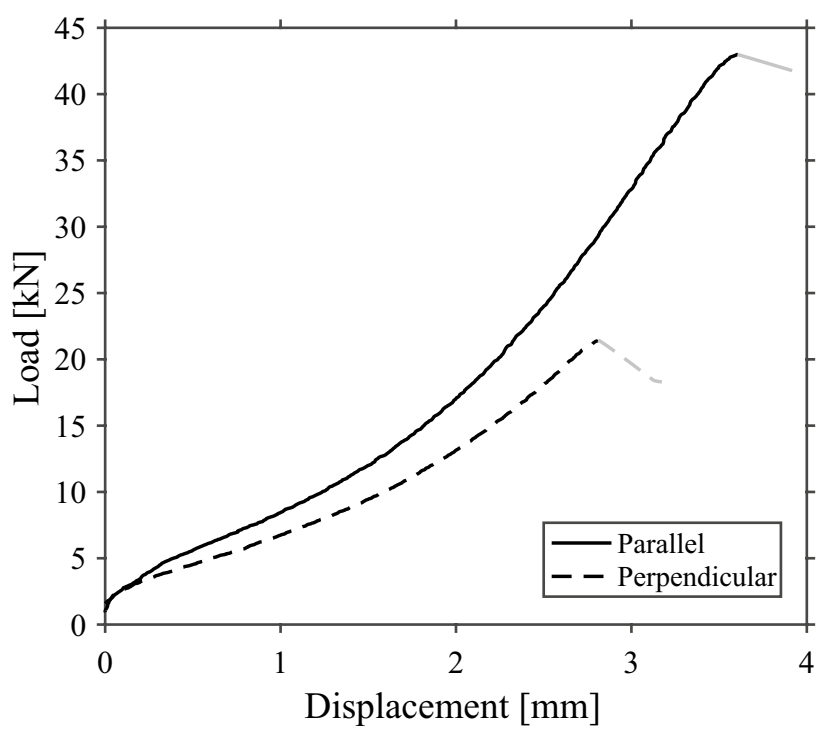

Fig. 7 Typical load-displacement curve for short term testing of SPDJ specimens loaded parallel and perpendicular to the grain. Grey lines are very fast failure propagation and should thus be considered brittle

The steel plate displacement was measured using linear potentiometers, for which typical results are found in Fig. 7. The behaviour resembles that of rubber in shear rather than timber, although the difference in stiffness is caused by the timber. The average stiffness of the parallel specimens was $12.6 \mathrm{kN} / \mathrm{mm}$ and $7.0 \mathrm{kN} / \mathrm{mm}$ for the perpendicular specimens, as determined assuming a linear force-displacement relation between $0.4 \mathrm{~F}_{\max }$ and $0.7 \mathrm{~F}_{\max }$ and where $F_{\max }$ is the ultimate load. The initial stiffness is considerably higher than the presented average, as can be seen in Fig. 7. 
Table 2 Time to failure for specimens loaded parallel and perpendicular to the grain at different load levels in percentage of average shortterm failure loads

\begin{tabular}{lllllr}
\hline Specimen & Load level (\%) & $\begin{array}{l}\text { Time to failure } \\
\min \end{array}$ & $\begin{array}{l}\text { Time to failure } \\
\max (\mathrm{h})\end{array}$ & $\begin{array}{l}\text { Time to failure } \\
\text { median }(\mathrm{h})\end{array}$ & COV (\%) \\
\hline Par-80 & 80 & $26 \mathrm{~min}$ & 406 & 26 & 120 \\
Par-60 & 60 & $292 \mathrm{~h}$ & 1111 & 839 & 45 \\
Par-50 & 50 & $37 \mathrm{~h}$ & 1210 & 772 & 40 \\
Perp-80 & 80 & $1 \mathrm{~min}$ & 541 & 0.3 & 290 \\
Perp-60 & 60 & $9 \mathrm{~min}$ & 2238 & 1712 & 50 \\
Perp-50 & 50 & $571 \mathrm{~h}$ & 2510 & 1299 & 35 \\
\hline
\end{tabular}

Ten specimens of each type and load level were tested, and thus minimum time to failure is also the 5th percentile
Fig. 8 Cumulative distribution of time to failure of the parallel (left) and perpendicular (right) test specimens, all three load levels
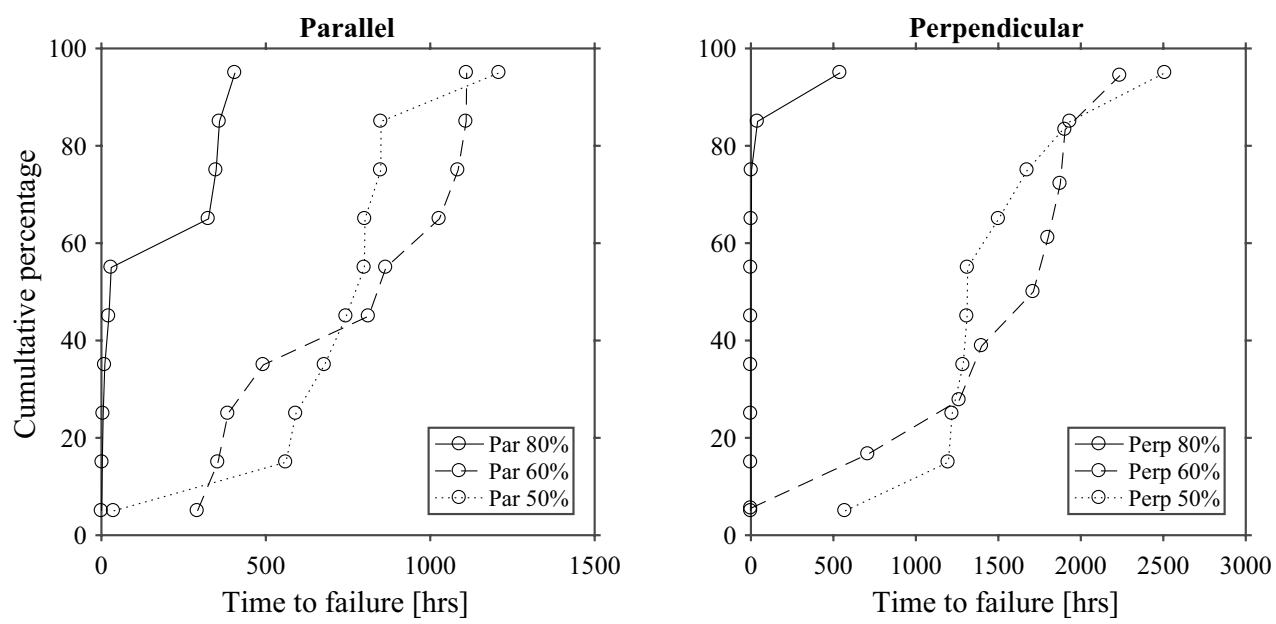

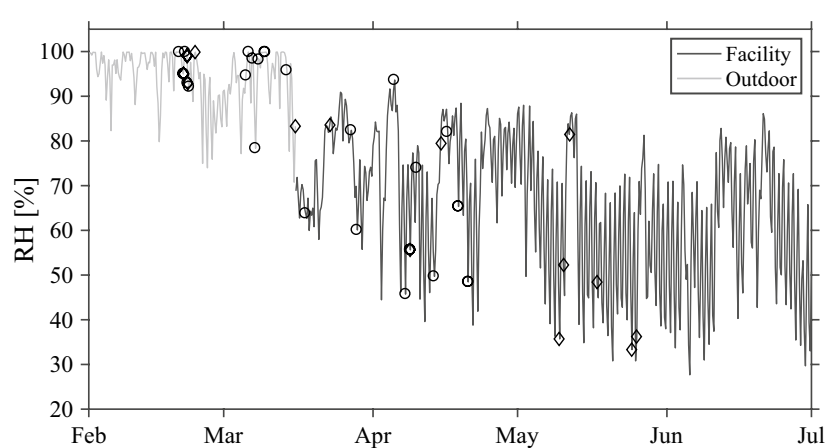

Fig. 9 Relative humidity within the test facility or outdoor close to the test facility during the long-term tests. Failures are indicated by circles and diamonds for specimens loaded parallel and perpendicular to the grain, respectively

\section{Results of long-term tests}

\subsection{Time to failure}

The long-term tests were all performed in outdoor sheltered conditions after 48-72 days of on-site conditioning in the facility described in Sect. 2 . The average specimen moisture content at time of test initialization was $15.9 \%$, i.e. +6.8 p.p. since production and +4.2 p.p. compared to short term tests. The specimens were loaded to $80 \%, 60 \%$ or $50 \%$ of the average short-term failure load presented in Table 1 in a fast ramp load, usually fully loaded within $1 \mathrm{~min}$. Testing of the $80 \%$ and $60 \%$ test specimens began in late February 2018, while the tests with the 50\% specimens started in late March. The results of the long-term tests are found in Table 2, as well as Figs. 8 and 9. A high variability in terms of time to failure was found.

From the results of the short-term loading, it was expected that $10 \%$ of the parallel to grain specimens and $20 \%$ of the perpendicular to grain specimens loaded to $80 \%$ would fail upon loading. It was found that $1 / 10 \mathrm{Par}-80$ specimens failed within $30 \mathrm{~min}$, while $6 / 10$ Perp- 80 specimens failed within $30 \mathrm{~min}$. It is thus plausible that the specimens loaded perpendicular to the grain were more sensitive to the fast ramp loading procedure used than the specimens loaded parallel to the grain. A single Perp-60 specimen also failed during loading.

Failure status was recorded every minute by a logging system. Additionally, daily visual inspections were ramped down to weekly inspections during the course of the testing. However, the logging system was inoperable during 
three time periods of 2-6 days during the entire test. Furthermore, some few specimens failed without activating the logging system, and these failures were thus discovered during the visual inspections. For the cases where manual logging was required, the time between last confirmed status and manual logging was chosen as failure time. This was done for a total of ten out of 60 DOL specimens.

The failure modes of the DOL specimens are similar to the failure modes of the short-term specimens. Due to the higher strength of the wood in shear parallel to the grain as compared to shear perpendicular to the grain, the specimens loaded parallel to the grain seem more prone to adhesive failure, while specimens loaded perpendicular to the grain show more shallow wood shear failures. Adhesives typically also show a time to failure effect (Frihart and Beecher 2016). This was observed in the specimens loaded perpendicular to the grain by a higher degree of adhesive failure surface found in the DOL specimens compared to short-term loading (average of $36 \%$ vs $12 \%$ ). However, no such change was found for the specimens loaded parallel to the grain. One of the specimens loaded perpendicular to the grain in the $60 \%$ load level group was removed from the analysis due to setup error.

A smaller than expected difference in terms of time to failure was found between the $60 \%$ and $50 \%$ load level specimens, regardless of the loading direction. The relative humidity during the test period is shown in Fig. 9, in which failure times are also included. Outdoor measurements recorded $1.2 \mathrm{~km}$ from the facility complement the facility measurements due to system failure.

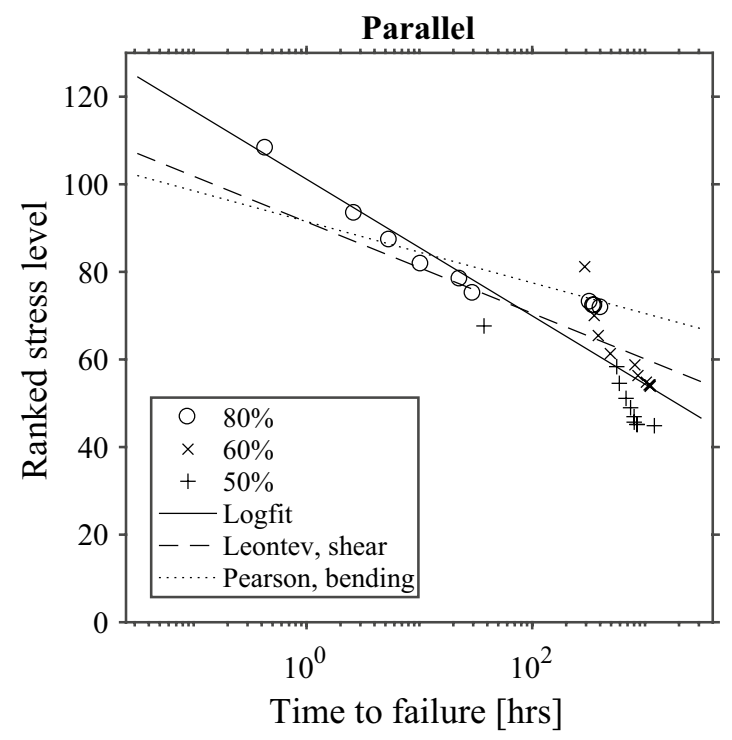

Fig. 10 Ranked stress level vs time of specimens loaded parallel to the grain (left) and perpendicular to the grain (right). Logfit refers to a linear logarithmic fit to test data, while two reference curves are
The data does not suggest a higher rate of failure during decreasing relative humidity. The lowest recorded moisture content of a single test specimen was $12.1 \%$ in early June, while the highest was $16.3 \%$, recorded at test start in February.

\subsection{Matching and fitting}

The aim of the study was to find a general strength reduction for a typical SPDJ subjected to load over time. The method of ranked stress level was adopted, based on the assumption that the specimen strength distribution is equal for all load level groups. The results of each group are sorted from low to high, and the load acting on the first failing specimen of each load level group is then divided by the failure load of the weakest short-term specimen to determine its ranked stress level. Such a ranked stress level thus differentiates the load levels based upon the average shortterm strength, which is useful in the stress level versus time to failure analysis shown in Fig. 10. It has previously been shown that linear-logarithmic functions are suitable to estimate the duration of load behaviour of timber (Hoffmeyer 1990). Such lin-log fits are also chosen for this study, since the statistical significance of the conducted tests is not high enough to suggest otherwise. Reference curves of the shear DOL behaviour of clear wood as determined by Leont'ev (1961) and bending DOL behaviour as compiled by Pearson (1972) are also shown in the figure, both determined parallel to the grain.

The empirical linear logarithmic fit is in general terms expressed as shown in Eq. (1), where $A$ and $B$ are fitting

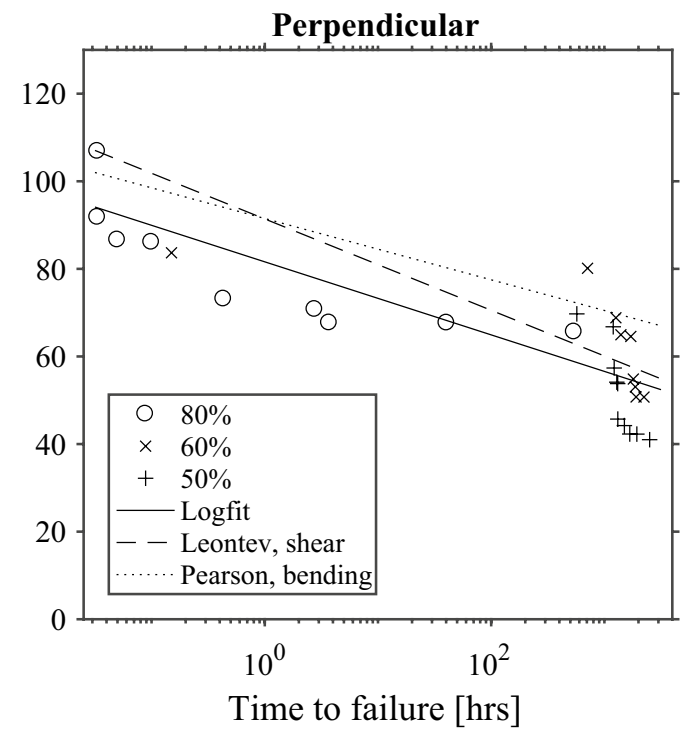

also plotted (Leont'ev 1961; Pearson 1972). The 100\% specimens are excluded due to other type of loading 
parameters, $t_{0}$ is a time reference here set to $t_{0}=1 \mathrm{~h}, f_{s, \text { Ramp }}$ is the fractile $s$ short-term ramp loading strength and $\sigma_{s, D O L}$ is the constant load that for strength fractile $s$ of the material is predicted to give a failure at time $t=t_{f}$

$\frac{\sigma_{s, D O L}}{f_{s, \text { Ramp }}}=A-B \log _{10}\left(t_{f} / t_{0}\right)$

With an $\mathrm{R}^{2}$ value of 0.78 and 0.73 for parallel and perpendicular tests, respectively, the logarithmic fitting parameters are found in Table 3.

Even though failure times did not exceed 4 months and thus not a full year cycle, the logarithmic functions can be extrapolated to obtain a rough estimate in order to be compared for a reference period of 50 years. The given logarithmic fits suggest the resulting stress levels at failure to be $13.2 \%$ and $34.6 \%$ for parallel and perpendicular SPDJ, respectively. The values given in Table 3 for references Leont'ev (1961) and Pearson (1972) correspond to $33 \%$ and $52 \%$ for shear and bending, respectively. The suggested reduction factor $\mathrm{k}_{\text {mod }}$ for the SPDJ in outdoor sheltered conditions are estimated to be in the range of 0.10 and 0.30 for SPDJ specimens loaded parallel and perpendicular, respectively. For reference, Eurocode assigns a $\mathrm{k}_{\text {mod }}$ factor of 0.5 for the corresponding climate class 3 , without differentiating for modes of loading (bending/ shear), nor for load to grain angle (parallel/perpendicular).

The ranked stress method is based upon the internal ranking of the grouped test results. The sensitivity of the estimated reduction factors $\mathrm{k}_{\text {mod }}$ (one for parallel to grain loading and one for perpendicular to grain loading) to this internal ranking was investigated by randomly deleting up to five individual test results in each group. For each such new combination of fictitious test results, the corresponding value of $\mathrm{k}_{\text {mod }}$ was calculated. The obtained distributions of $\mathrm{k}_{\text {mod }}$ were then statistically evaluated. For the parallel to grain loaded specimens, the statistical analysis suggests an average stress level at failure of $13.9 \%$ with a standard deviation of 0.068 . Corresponding values for the perpendicular specimens are $35.5 \%$ and 0.026 . Using the identified $\mathrm{k}_{\text {mod }}$ distributions, the abovementioned estimates of the reduction factors of 0.10 and 0.30 correspond to

Table 3 Empirical parameters to linear logarithmic fit to DOL testing of the SPDJ

\begin{tabular}{lll}
\hline & $A$ & $B$ \\
\hline Parallel & 101.2 & 15.60 \\
Perpendicular & 81.6 & 8.34 \\
Ref shear (Leont'ev 1961) & 91.4 & 10.4 \\
Ref bending (Pearson 1972) & 91.5 & 7 \\
\hline
\end{tabular}

the percentiles of $20 \%$ and $1.5 \%$ for the perpendicular and parallel specimens, respectively.

\subsection{Long term deformations}

Displacement of the steel shear plate was measured every minute during the test period for one specimen in each group. Plotted in Fig. 11 is the average of two linear potentiometers used to measure on each side of a specimen. The raw measurement data contains a few time regions with unrealistic deformation variations, probably due to an unsteady power supply at the test facility. One region of obviously corrupted data has been removed. However, some minor anomalies are still visible in Fig. 11 such as the large and fast variation of displacement, which can be seen in all readings as highlighted by dotted circles. All circled data were recorded during the same time period (different start dates), for which the variation is certainly not due to the mechanical loading. The variation might be due to moisture changes, but this is unlikely since no large variations in climate were recorded during the time period in question. Furthermore, a moisture variation would have a more significant effect on the specimens loaded perpendicular to the grain as the measurement setup here is more influenced by shrinkage and swelling, which is not the case in the readings.

A stiffness discrepancy is shown in Fig. 11 for the parallel specimen. The single Par-50 specimen shows a larger deformation than the heavier loaded Par- 60 specimen. However, postfailure inspection shows how the Par-50 specimen included an unsound knot on one side of the bond line, and some 5\% area of vulcanization failure on the other. These defects decrease the effective bond area and thus increase the deformation. No significant defects were visible in the $60 \%$ specimen.

The results are also tabulated in Table 4, where it is evident that $50 \%$ load level specimens experienced more creep than the $60 \%$ specimens, despite direction of load. This unexpected result can possibly be attributed to material variation.

The initial deformation is defined as the deformation after 10 min of constant loading. The normalized creep factor is defined in Eq. (2), which is valid since the thickness of the rubber layer is $1 \mathrm{~mm}$

creep factor $=\frac{\delta-\delta_{0}}{\delta_{0}}=\frac{\varepsilon-\varepsilon_{0}}{\varepsilon_{0}}$

\section{Effects of long-term outdoor sheltered storage}

In addition to the DOL study, the degradation of short-term strength by 1 year of outdoor sheltered storage was investigated in a comparative manner between the SPDJ and a similar joint but without the rubber layer in the bond line 

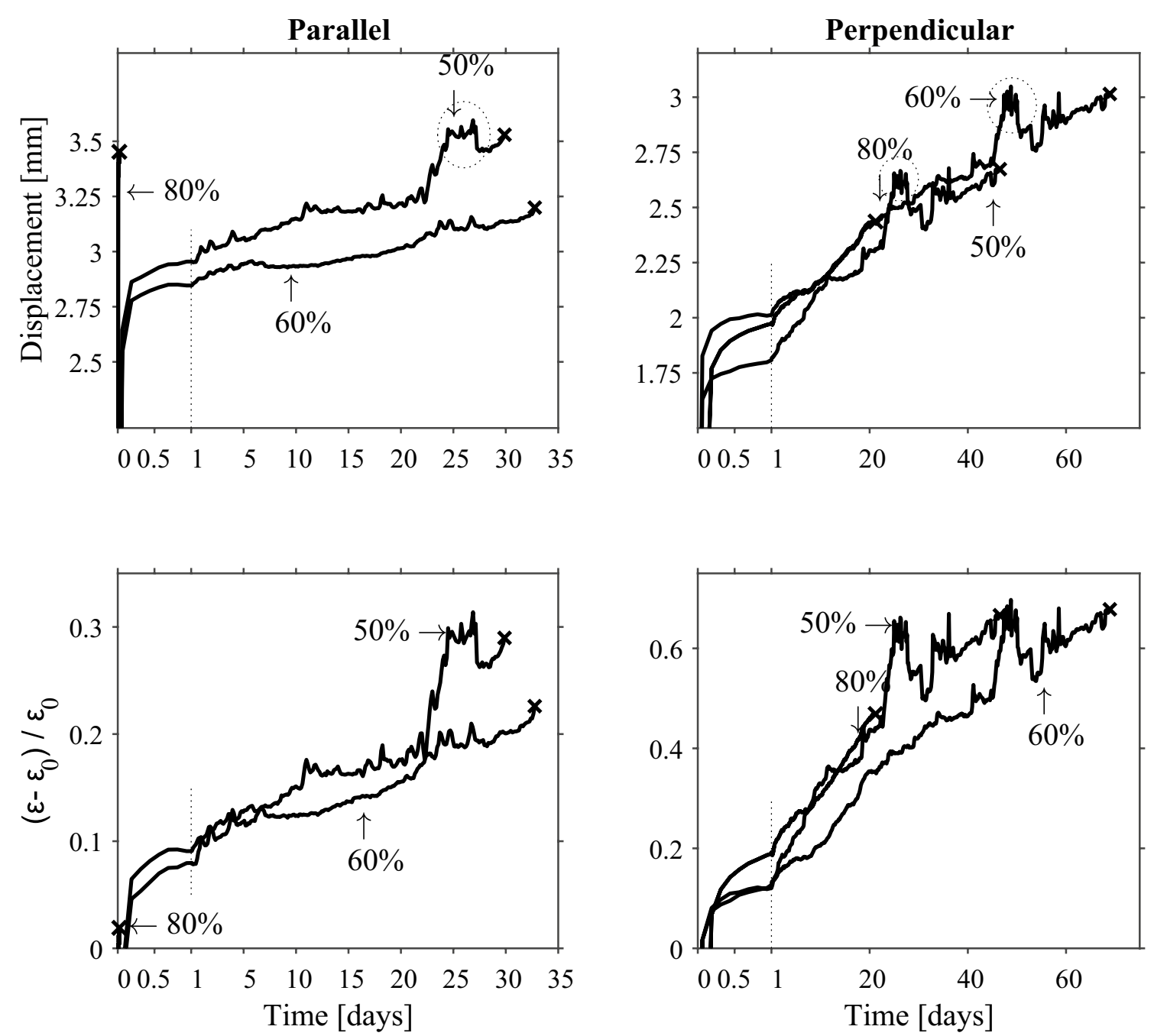

Fig. 11 Displacement (top) and normalized creep factor (bottom) over time for SPDJ specimens loaded parallel (left) and perpendicular (right) to grain at different load levels. Note the different time scales before and after 1 day

Table 4 Deformations and creep data for parallel and perpendicular test specimens at different load levels in percentage of average shortterm failure loads

\begin{tabular}{llllll}
\hline Specimen & Load level (\%) & Def $10 \mathrm{~min}$ & Def $24 \mathrm{~h}$ & Def at failure & $\begin{array}{r}\text { Creep fact. } \\
\text { @ 20 days }\end{array}$ \\
\hline Par-80 & 80 & 3.38 & - & $3.45(0.5 \mathrm{~h})$ & - \\
Par-60 & 60 & 2.61 & 2.85 & $3.20(815 \mathrm{~h})$ & 0.15 \\
Par-50 & 50 & 2.74 & 2.96 & $3.53(745 \mathrm{~h})$ & 0.17 \\
Perp-80 & 80 & 1.66 & 1.97 & $2.44(540 \mathrm{~h})$ & 0.45 \\
Perp-60 & 60 & 1.80 & 2.02 & $3.01(1905 \mathrm{~h})$ & 0.34 \\
Perp-50 & 50 & 1.60 & 1.81 & $2.67(1290 \mathrm{~h})$ & 0.43 \\
\hline
\end{tabular}

All deformations are specified in $\mathrm{mm}$, and the total duration time to failure is shown in parentheses. The creep factor is defined as deformation at failure divided by initial 10-min deformation
(SPDJ-wr). For this purpose, three specimens of each type were produced and tested.

The average moisture content of the original specimens during testing was $11.3 \%$ and $8.6 \%$ for the SPDJ and SPDJ-wr specimens, respectively. The specimens stored for 1 year (379 days) had an average moisture content of $16 \%$ during testing, for which the results are found in Table 5. 
A general strength degradation of the specimens was found after exposure to natural moisture fluctuations. However, a larger degradation was expected for the specimens without rubber than for the specimens with rubber, as the rubber layer should accommodate for moisture movements in the timber and possibly minimise cracking. This effect is expected to be more pronounced for larger test specimens than the $65 \times 65 \mathrm{~mm}^{2}$ used.

Although it is difficult to unequivocally distinguish the effect of the storage from the effect of different moisture contents during testing, an estimate can be obtained using Eq. 3 (Gehri 2010). The relation suggests that for a moisture content between 12 and 20\%, the shear strength decreases by $2.5 \%$ per $1 \%$ increase in moisture content. The equation is based upon clear wood specimens tested in parallel shear, where $f_{v, M C \%}$ is the shear strength at a given moisture content $M C(\%) . f_{v, \text { green }}$ is the shear strength of green wood, and $M_{p}$ the moisture content at the intersection of a horizontal line representing the strength of green wood and an inclined line representing the logarithm of the strength-moisture content relationship for dry wood, i.e. slightly less than the fibre saturation point and typically $M_{p} \approx 25$

$f_{v, M C \%}=f_{v, 12 \%}\left(\frac{f_{v, 12 \%}}{f_{v, \text { green }}}\right)^{\left(\frac{12-M C}{M_{p}-12}\right)} \approx f_{v, 12 \%}(1-0.025(M C-12 \%))$

A $12 \%$ strength reduction due to increased moisture content is expected for the SPDJ by means of Eq. (3), while $17 \%$ for the SPDJ-wr. It can thus be concluded that, for parallel shear, the SPDJ-wr can be considered unaffected by the storage, while a reduction was found for the SPDJ contrary to expectations. However, the tests perpendicular to grain indeed showed a larger reduction for the specimens without rubber.

Table 5 Average short-term strength of the SPDJ after unloaded outdoor sheltered storage for 1 year, with and without a rubber layer in the bond line (SPDJ and SPDJ-wr, respectively)

\begin{tabular}{|c|c|c|}
\hline & SPDJ & SPDJ-wr \\
\hline \multicolumn{3}{|l|}{ Parallel } \\
\hline New & $39 \mathrm{kN}^{\mathrm{a}}(12 \%)$ & $24 \mathrm{kN}(42 \%)$ \\
\hline 1 year & 28 kN (17\%) & $21 \mathrm{kN}(22 \%)$ \\
\hline Decrease & $29 \%$ & $13 \%$ \\
\hline \multicolumn{3}{|c|}{ Perpendicular } \\
\hline New & $20 \mathrm{kN}^{\mathrm{a}}(18 \%)$ & $19 \mathrm{kN}(16 \%)$ \\
\hline 1 year & 19 kN (7\%) & $12 \mathrm{kN}(20 \%)$ \\
\hline Decrease & $4 \%$ & $40 \%$ \\
\hline
\end{tabular}

Coefficient of variation in parentheses

${ }^{a}$ Average of ten specimens, otherwise average of 3

\section{Evaluation of DOL effects on the SPDJ}

The results of this study comprise experimental analyses of the shear plate dowel joint subjected to long term loading. The design of the joint entails a close to uniform shear stress being applied to the GLT body, and thus it is expected that the SPDJ has an upper bound performance level being defined by the shear behaviour of timber. Any other failure mode than shallow wood failure in the bond line should thus decrease the strength of the joint in comparison.

The short-term strength results in Fig. 4 show that the SPDJ is stronger in shear than the small clear wood specimens in pure shear (Berblom Dahl 2009). It is reasonable to believe that this difference is in part due to the difference between timber and clear wood, but also indicates that the failure of the bond line is not a typical pure shear failure. This reasoning is also evident in the fact that the characteristic strength values of longitudinal and rolling shear in Eurocode surpass the 5th percentile of the presented clear wood strengths in Fig. 4. It is found that the 5th percentile of the tested SPDJ specimens exceeds the characteristic strength values in Eurocode in terms of short-term strengths, with an increase of $25 \%$ and $80 \%$ for parallel and perpendicular direction, respectively. Note that this is despite the high degree of adhesive failure in the bond line.

A high degree of bond failure between the adhesive and rubber was found, something which can be avoided by a better quality control of the pre-treatment of the rubber. However, it should be noted that high average shear stress at failure was achieved compared to strength values for design. The mixed type of bond line failure mode in the DOL testing was similar to that in the short-term tests. This suggests that any specific failure mode was no more prone to time effects than another and that no specific failure mode is considerably weaker than another. It is thus difficult to identify a specific failure initiation mode.

Based upon the findings of Leont'ev (1961), it is reasonable to expect that a perfectly manufactured SPDJ loaded parallel to grain would still be limited to a $\mathrm{k}_{\bmod }$ of approximately 0.3 , if the bonded plates were large enough to minimize the influence of peel stresses. However, using the proposed bonding technique and material in outdoor sheltered conditions, a reduction factor $\mathrm{k}_{\text {mod }}$ of 0.1 was found for parallel to grain loading, while a $\mathrm{k}_{\text {mod }}$ factor of 0.3 was found for perpendicular to grain loading. These $\mathrm{k}_{\bmod }$ values should be regarded as estimates, as the test duration was too short to establish such reduction factors with satisfying accuracy. The longest recorded test period did not exceed 4 months, and thus did not experience a full year cycle of the varying climate common to the test 
site. It is possible that these results are overestimating the reduction, as the first moisture variation typically causes increased creep rates and microdamage (Van de Kuilen 1999).

Van de Kuilen (1999) conducted comparative duration of load tests on shear connectors in controlled and uncontrolled indoor climate with a total test duration of over 10 years. It was shown how not only timber in bending, but also different types of shear connectors are strongly and negatively influenced by a varying relative humidity. A decrease of $\mathrm{k}_{\text {mod }}$ by approximately $10 \%$ was proposed for connectors with large shear areas, which is considerably less than found in this study. However, it is difficult to quantify the interaction of the dowels used in the split ring and toothed plate connections. It is reasonable to anticipate that an indoor climate would cause a smaller reduction in strength and thus a higher $\mathrm{k}_{\text {mod }}$ factor, but Van de Kuilen also presents how a moisture content variation of only $1 \%$ is sufficient to induce mechano-sorptive deformation, a variation, which indeed also occurs in indoor climate.

In the recorded deformations of the shear connectors (Van de Kuilen 1999), a second process of higher creep rate was triggered by the moisture variations of an uncontrolled climate after approximately 200 days. The creep results of the SPDJ do not indicate such a second process but instead the specimens maintained a high creep rate throughout the relatively short test period. However, the variation in moisture content from test start in combination with a high load level might suggest that such a second phase was initialized early in the test duration, rather than suggesting that the phases did not occur for the current tests.

Although this study might indicate that shear perpendicular to grain is to some degree better than shear parallel to grain as regards DOL behaviour, it must be concluded that the SPDJ without screws is not efficient in terms of long duration loads in outdoor sheltered conditions, and that further studies are needed in order to verify the use in other climates.

Such a further duration of load study is currently ongoing at Nanjing Tech University, China, where lap joints with a resilient bond line using rubber are tested under climate control. In addition to the resilient bond line with a total shear area of $12,800 \mathrm{~mm}^{2}$ (approximately double the size as compared to this study), the bond lines also include screws. The first specimen loaded to $60 \%$ has failed after 391 days. Additionally, a single very small-scale resilient lap joint $\left(200 \mathrm{~mm}^{2}\right)$ was loaded to $25 \%$ of short term strength in indoor climate and unloaded after 8 years without failure, succeeding the work of Danielsson and Björnsson (2005). The bonding technique used for these two studies is the same as used in this study, suggesting a higher $\mathrm{k}_{\text {mod }}$ for indoor climate.

\section{Conclusion}

During the course of this study a lack of knowledge and empirical evidence on duration of load effects in timber for shear loading became apparent. Published research is inconclusive in terms of the duration of load behaviour of shear strength compared to bending strength. More studies in this field are advisable.

In terms of the shear plate dowel joint, it was found that the characteristic short-term strength of the small-scale shear plate dowel joints is higher than the characteristic shear strength of timber according to Eurocode. However, the duration of load behaviour of the shear plate dowel joint was found inferior to comparative connection types. A linear logarithmic fit to ranked stress data over time suggests a significant duration of load reduction factor $\mathrm{k}_{\text {mod }}$ of 0.10 and 0.30 for parallel and perpendicular SPDJ, respectively. This was found for specimens without screws in outdoor sheltered conditions. This is to be considered an estimate based on a 50-year extrapolation of 4-month data. The shear plate dowel joint, as produced in this study without any improvements, is not recommended for structural applications in outdoor sheltered conditions.

Acknowledgements Open access funding provided by Lund University. The financial support provided by Stiftelsen Nils och Dorthi Troëdssons forskningsfond through grant 893-16 is gratefully acknowledged. The authors would like to thank Thomas Johansson at Moelven Töreboda AB for delivering the GLT and Ante Salomonsson at Sika for adhesives and expertise. This study has also been made possible by the Swedish Infrastructure for Ecosystem Science (SITES), in this case by Asa Research Station. Special thanks to the staff at the research station as well as to Michael Lempart and Jessica Dahlström, Structural Mechanics at Lund University, for their work on the DOL measurement system. Associate Professor Huifeng Yang at Nanjing Tech University is kindly acknowledged for sharing unpublished data.

Open Access This article is distributed under the terms of the Creative Commons Attribution 4.0 International License (http://creativeco mmons.org/licenses/by/4.0/), which permits unrestricted use, distribution, and reproduction in any medium, provided you give appropriate credit to the original author(s) and the source, provide a link to the Creative Commons license, and indicate if changes were made.

\section{References}

Austrell P-E (1997) Modelling of elasticity and damping for filled elastomers, PhD thesis, Lund University. ISSN 0281-6679

Berblom Dahl K (2009) Mechanical properties of clear wood from Norway spruce. PhD thesis, Norwegian University of Science and Technolog, Trondheim, Norway. ISBN 978-82-471-1911-2

Crocetti R, Axelson M, Sartori T (2010) Strengthening of large diameter single dowel joints, SP Technical Research Institute of Sweden. Report 2010:14

Danielsson H, Björnsson P (2005) Strength and creep analysis of glued rubber foil timber joints, Master thesis, Lund University 
Frihart CR, Beecher JF (2016) Factors that lead to failure with wood adhesive bonds. World Conference on Timber Engineering, WCTE 2016, August 22-25, 2016, Vienna, Austria

Gehri E (2010) Shear problems in timber engineering - analysis and solutions. In: Proceedings of 11th World Conference on Timber Engineering, Riva del Garda

Gerhards CC (1977) Effect of duration and rate of loading on strength of wood and wood-based materials. Forest Products Lab, Madison

Gustafsson PJ (2007) Tests of full size rubber foil adhesive joints, Lund University. ISSN 0281-6679

Hoffmeyer P (1990) Failure of wood as influenced by moisture and duration of load. PhD thesis, State University of New York. College of Environmental Science and Forestry, Syracuse

Kobel P (2011) Modelling of strengthened connections for large span truss structures, Master Thesis, Lund University

Larsson G (2016) High capacity timber lap joints and the shear plate dowel joint. Licentiate Thesis, Lund University

Larsson G, Gustafsson PJ, Crocetti R (2018) Use of a resilient bond line to increase strength of long adhesive lap joints. Eur J Wood Prod 76:401-411

Leont'ev N (1961) Long term resistance of spruce wood to shear along the grain. Lesn Z Archanel'sk 4(4):122-124
Madsen B (1971) Duration of load tests for dry lumber in bending, University of British Columbia, Department of Civil Engineering

Madsen B (1975) Duration of load tests for dry lumber subjected to shear. University of British Columbia, Department of Civil Engineering. Structural research series, no. 6

Pearson R (1972) The effect of duration of load on the bending strength of wood. Holzforschung 26(4):153-158

Spencer RA, Madsen B (1986) Duration of load tests for shear strength. Can J Civ Eng 13(2):188-195

Van de Kuilen JWG (1999) Duration of load effects in timber joints. $\mathrm{PhD}$ thesis, Technical University of Delft

Wood LW (1951) Relation of strength of wood to duration of load. Forest Products Laboratory, Madison (Rep. No. R1916)

Yang H, Crocetti R, Larsson G, Gustafsson P-J (2015) Experimental study on innovative connections for large span timber truss structures. Proceedings of the IASS Working Groups, 12(18). Tokyo, Japan

Publisher's Note Springer Nature remains neutral with regard to jurisdictional claims in published maps and institutional affiliations. 